\title{
Antibiotic Susceptibility Patterns of Bacterial Isolates from Pus Samples in a Tertiary Care Hospital of Punjab, India
}

\author{
Rugira Trojan, ${ }^{1}$ Lovely Razdan, ${ }^{2}$ and Nasib Singh ${ }^{3}$ \\ ${ }^{1}$ Department of Paramedical Sciences, Lovely Professional University, Punjab, India \\ ${ }^{2}$ Department of Pathology, Patel Hospital, Jalandhar, Punjab, India \\ ${ }^{3}$ Department of Microbiology, Eternal University, Baru Sahib, Himachal Pradesh, India \\ Correspondence should be addressed to Nasib Singh; kamalgollen@gmail.com
}

Received 18 July 2016; Accepted 19 September 2016

Academic Editor: Jianying Zhang

Copyright (C) 2016 Rugira Trojan et al. This is an open access article distributed under the Creative Commons Attribution License, which permits unrestricted use, distribution, and reproduction in any medium, provided the original work is properly cited.

\begin{abstract}
We determined the prevalence and antibiotic susceptibilities patterns of bacterial isolates from pus samples collected from patients in a tertiary care hospital of Punjab, India. E. coli was the most prevalent pathogen (51.2\%) followed by Staphylococcus aureus (21\%), Klebsiella pneumoniae (11.6\%), Pseudomonas aeruginosa (5.8\%), Citrobacter spp. (3.5\%), Acinetobacter baumannii (2.3\%), Proteus mirabilis (2.3\%), and Streptococcus spp. (2.3\%). E. coli, K. pneumoniae, A. baumannii, and Citrobacter isolates were resistant to multiple antibiotics including higher generation cephalosporins. S. aureus and Streptococcus isolates were sensitive to cloxacillin and vancomycin. However, P. aeruginosa, P. mirabilis, and Streptococcus isolates were found to be less resistant to the spectrum of antibiotics tested. Overall, our findings indicate the prevalence of resistance to different classes of antibiotics in bacterial isolates from pus infections and hence highlight the need for effective surveillance, regulator reporting, and antibiogram-guided antibiotic prescription.
\end{abstract}

\section{Introduction}

The human skin and soft tissue infections (SSTIs) caused by microbial pathogens during or after trauma, burn injuries, and surgical procedures result in the production of pus, a white to yellow fluid comprised of dead WBCs, cellular debris, and necrotic tissues [1-3]. Both aerobic and anaerobic bacteria have been implicated in wound infections which commonly occur under hospital environment and result in significant morbidity, prolonged hospitalization, and huge economic burden [4]. The emergence antibiotic resistance and its rapid spread of among pathogenic bacterial isolates are considered as grave threats to the public health worldwide. During the last few decades, multidrug-resistant Gramnegative bacterial strains such as Acinetobacter baumannii, E. coli, Klebsiella pneumoniae, Pseudomonas aeruginosa, and Gram-positive methicillin-resistant Staphylococcus aureus (MRSA) were increasingly associated with pus infections under hospital settings due to extensive misprescription and inadequate dose regimen of antibiotics [5-7]. Rapid emergence of multidrug-resistant bacteria poses a serious threat to public health globally due to the limited treatment options and lukewarm discovery of new classes of antibiotics $[7,8]$. The objective of this study is to characterize the pyogenic bacteria from pus samples and to determine their antibiotic susceptibilities to various generations of antibiotics commonly used in chemotherapeutic interventions.

\section{Materials and Methods}

2.1. Sample Collection and Characterization. A total of 143 pus samples were collected by sterile syringe aspiration $(n=$ $41)$ and by sterile swabs $(n=102)$ from inpatients and outpatients of different wards of Patel Hospital, Jalandhar, Punjab (India), over a period of 5 months from January 2014 to May 2014 in accordance with standard protocols and ethical guidelines. Pus samples were collected from skin (furuncles, pustules, and abrasions), nasal wounds, ears, legs, internal organs (lungs, kidney, and bladder), and catheters. Pus samples were kept in Cary-Blair transport medium until processed for Gram staining and culturing. The samples 
were aseptically inoculated on blood agar (with 5\% sheep blood) and MacConkey agar plates, incubated aerobically at $35^{\circ} \mathrm{C}-37^{\circ} \mathrm{C}$ for $24-48 \mathrm{~h}$. Identification and characterization of isolates were performed on the basis of Gram staining, microscopic characteristics, colony characteristic, and biochemical tests using standard microbiological methods.

2.2. Antimicrobial Agents. Antibiotics discs containing amikacin $(30 \mu \mathrm{g})$, amoxicillin-clavulanic acid $(30 \mu \mathrm{g})$, aztreonam $(30 \mu \mathrm{g})$, ampicillin $(10 \mu \mathrm{g})$, azithromycin $(30 \mu \mathrm{g})$, cefepime $(30 \mu \mathrm{g})$, Cefoperazone/Sulbactam $(75 / 30 \mu \mathrm{g})$, ceftriaxone $(30 \mu \mathrm{g})$, cefotaxime $(30 \mu \mathrm{g})$, cefuroxime $(30 \mu \mathrm{g})$, cephalexin $(30 \mu \mathrm{g})$, ciprofloxacin $(1 \mu \mathrm{g})$, clindamycin $(2 \mu \mathrm{g})$, cloxacillin $(30 \mu \mathrm{g})$, trimethoprim/sulfamethoxazole $(25 \mu \mathrm{g})$, ertapenem $(10 \mu \mathrm{g})$, erythromycin $(15 \mu \mathrm{g})$, gatifloxacin $(5 \mu \mathrm{g})$, gentamicin $(10 \mu \mathrm{g})$, imipenem $(10 \mu \mathrm{g})$, levofloxacin $(5 \mu \mathrm{g})$, linezolid $(30 \mu \mathrm{g})$, meropenem $(10 \mu \mathrm{g})$, netilmicin $(30 \mu \mathrm{g})$, norfloxacin $(10 \mu \mathrm{g})$, ofloxacin $(5 \mu \mathrm{g})$, piperacillin-tazobactam $(100 / 10 \mu \mathrm{g})$, teicoplanin $(30 \mu \mathrm{g})$, tetracycline $(30 \mu \mathrm{g})$, and vancomycin $(30 \mu \mathrm{g})$ were obtained from Himedia Laboratories (Mumbai, India) and used as per manufacturer's instructions.

2.3. Antibiotics Susceptibility Testing. Antibiotic susceptibilities of bacterial isolates were determined according to the method recommended by the Clinical and Laboratory Standards Institute [9]. Briefly, inocula were prepared for each bacterial isolate by adjusting the turbidity to $0.5 \mathrm{McF}$ arland standard and spread on Muller-Hinton agar plates. Antibiotic discs (Himedia, Mumbai, India) were placed on the agar plates and incubated overnight at $37^{\circ} \mathrm{C}$ for $24 \mathrm{~h}$. The zones of inhibition were measured and the isolates were classified as sensitive, intermediate, and resistant according to CLSI tables and guidelines [9].

\section{Results and Discussion}

Of the 143 pus samples collected from different wards of the hospital, 86 samples (60.1\%) showed bacterial growth after $24-48 \mathrm{~h}$ of incubation whereas 57 samples (39.9\%) were negative for growth. Based on Gram staining, morphological features, culture characteristics, and biochemical characterization, the bacterial isolates were assigned to eight bacterial species. E. coli was the most frequent pathogen as revealed by $51.2 \%$ occurrence followed by $S$. aureus $(21 \%)$, K. pneumoniae (11.6\%), P. aeruginosa (5.8\%), and Citrobacter spp. (3.5\%) and approximately $2.3 \%$ each was represented by A. baumannii, P. mirabilis, and Streptococcus spp. (Figure 1). Gram-negative bacteria were the dominant isolates (77\%) from pus samples compared to Gram-positive bacteria which are in agreement to several earlier studies. Our findings correlate with Zhang et al. [10] who reported predominance of E. coli, S. aureus, K. pneumoniae, and P. aeruginosa in pus samples from patients with severe intra-abdominal infection. In another study, $S$. aureus was the dominant bacterial species from wounds followed by $P$. aeruginosa, $P$. mirabilis, E. coli, and Corynebacterium spp. [11]. According to Dryden [12], S. aureus and MRSA are major cause of soft tissue infections in hospitalized patients. Several other
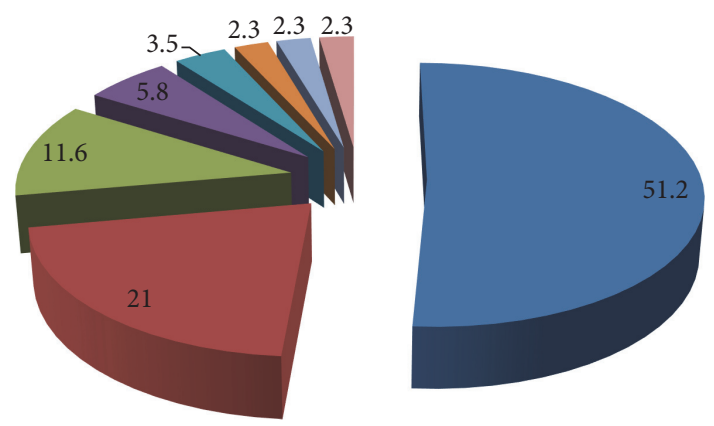

E. coli
- Staphylococcus aureus
- Klebsiella pneumoniae
- Pseudomonas aeruginosa

- Citrobacter

- Proteus mirabilis

- Acinetobacter baumannii

- Streptococcus

FIgURE 1: Distribution of bacterial pathogens (\%) isolated from pus samples at a tertiary care hospital in Punjab, India.

reports have also implicated Pseudomonas, Staphylococcus, Streptococcus, Klebsiella, and E. coli in wound infections $[6,13]$. Antibiogram results from the present study show that E. coli was more resistant to amoxicillin-clavulanic acid, cephalosporins, while being least resistant to amikacin, imipenem, gentamicin, and meropenem (Table 1). On the other hand, A. baumannii showed extensive multidrug resistance pattern as it was resistant to all the antibiotics. $P$. aeruginosa was more susceptible to tested antibiotics compared to K. pneumoniae. Both species showed resistance to cephalosporins. Previous studies from Canada, Croatia, and Latin America found P. aeruginosa isolates resistant to carbapenems, aminoglycosides, and ciprofloxacin but not to piperacillin $[14,15]$. Citrobacter isolates showed resistance to eight antibiotics whereas they were moderately susceptible to other antibiotics. S. aureus was highly susceptible to vancomycin (100\%), linezolid (100\%), imipenem (89\%), and meropenem (84\%) while it showed resistance to ampicillin, amoxicillin-clavulanic acid, ciprofloxacin, and azithromycin. Unlike some reports in which MRSA was associated with wound infections $[16,17]$, our findings revealed susceptibility in $S$. aureus isolates towards cloxacillin and cephalosporins. P. mirabilis and Streptococcus isolates, however, exhibited minimal resistance and were susceptible to most of the antibiotics (Table 1). Both Gram-positive isolates were fully susceptible to vancomycin and linezolid.

This study provides the evidence of high prevalence of antibiotic resistant bacteria in pus samples of patients collected from a tertiary care hospital environment. Our findings indicate the predominance of E. coli among the bacterial isolates of pus. The prevalence and antibiotics resistance patterns of pyogenic bacterial isolates usually exhibit variability according to geographic areas and climate conditions. Existence of high drug resistance to multiple antibiotics in E. coli, S. aureus, $K$. pneumoniae, and $P$. aeruginosa isolates from pus samples in this study and several other related reports points towards negligence on patients part, incomplete treatment schedules, antibiotics misuse, selfprescription, misprescription, lack of regional antibiogram 


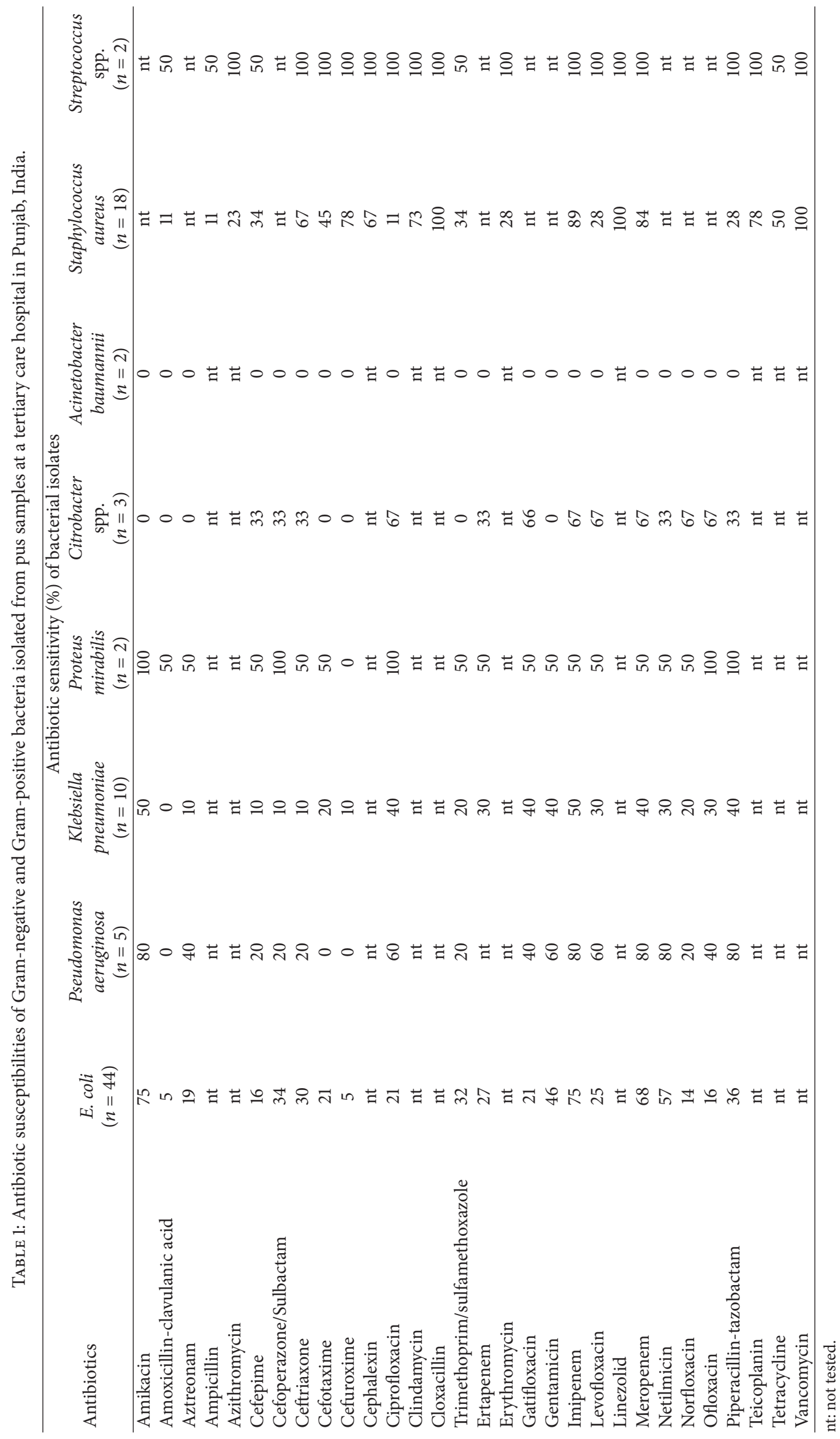


data, and limited knowledge about multidrug-resistant isolates and antimicrobial resistance among clinicians. Updated knowledge of antimicrobial susceptibility profiles of clinical isolates will not only assist in designing the most appropriate dose-regimen and treatment schedule against wound infections but also help in curbing the alarmingly expanding menace of drug resistance.

\section{Conclusion}

In conclusion, pyogenic wound infections were found prevalent in the tertiary care hospital and E. coli isolates showed highest incidence followed by $S$. aureus, $P$. aeruginosa, $K$. pneumoniae, A. baumannii, Citrobacter, P. mirabilis, and Streptococcus spp. Bacterial isolates exhibited high to moderate levels of resistance against different classes of antibiotics. The susceptibility data from this report may be worth consideration while implementing empiric treatment strategies for pyogenic infections. At the same time, strict health policies should also be implemented to regulate the purchase and prescription and restrict the unsupervised antibiotic use as well as continuous monitoring and reporting antibiotic resistance.

\section{Disclosure}

Present address of Rugira Trojan is School of Pharmacy, Mount Kenya University (Kigali campus), Rwanda.

\section{Competing Interests}

The authors do not have competing interests.

\section{Acknowledgments}

Rugira Trojan was financially supported by a study grant from the Ministry of Education, Republic of Rwanda. The authors are thankful to the Chancellor of Lovely Professional University (Punjab) and Director of Patel Hospital, Jalandhar (Punjab), for providing necessary facilities during this study.

\section{References}

[1] A. L. Cogen, V. Nizet, and R. L. Gallo, "Skin microbiota: a source of disease or defence?" British Journal of Dermatology, vol. 158, no. 3, pp. 442-455, 2008.

[2] M. S. Dryden, "Complicated skin and soft tissue infection," Journal of Antimicrobial Chemotherapy, vol. 65, supplement 3, pp. iii35-iii44, 2010.

[3] A. Scalise, A. Bianchi, C. Tartaglione et al., "Microenvironment and microbiology of skin wounds: the role of bacterial biofilms and related factors," Seminars in Vascular Surgery, vol. 28, no. 3-4, pp. 151-159, 2015.

[4] P. G. Bowler, B. I. Duerden, and D. G. Armstrong, "Wound microbiology and associated approaches to wound management," Clinical Microbiology Reviews, vol. 14, no. 2, pp. 244-269, 2001.
[5] L. B. Rice, "Antimicrobial resistance in gram-positive bacteria," The American Journal of Medicine, vol. 119, no. 6, supplement 1 , pp. S11-S19, 2006.

[6] A. M. Misic, S. E. Gardner, and E. A. Grice, "The Wound Microbiome: modern approaches to examining the role of microorganisms in impaired chronic wound healing," Advances in Wound Care, vol. 3, no. 7, pp. 502-510, 2014.

[7] J. Iredell, J. Brown, and K. Tagg, "Antibiotic resistance in Enterobacteriaceae: mechanisms and clinical implications," British Medical Journal, vol. 352, Article ID h6420, 2016.

[8] E. Cerceo, S. B. Deitelzweig, B. M. Sherman, and A. N. Amin, "Multidrug-resistant gram-negative bacterial infections in the hospital setting: overview, implications for clinical practice, and emerging treatment options," Microbial Drug Resistance, vol. 22, no. 5, pp. 412-431, 2016.

[9] CLSI, "Performance standards for antimicrobial susceptibility testing," Twentieth informational supplement, Clinical and Laboratory Standards Institute Doc. M100eS20, 2010.

[10] S. Zhang, L. Ren, Y. Li et al., "Bacteriology and drug susceptibility analysis of pus from patients with severe intra-abdominal infection induced by abdominal trauma," Experimental and Therapeutic Medicine, vol. 7, no. 5, pp. 1427-1431, 2014.

[11] L. J. Bessa, P. Fazii, M. Di Giulio, and L. Cellini, "Bacterial isolates from infected wounds and their antibiotic susceptibility pattern: some remarks about wound infection," International Wound Journal, vol. 12, no. 1, pp. 47-52, 2015.

[12] M. S. Dryden, "Skin and soft tissue infection: microbiology and epidemiology," International Journal of Antimicrobial Agents, vol. 34, supplement 1, pp. S2-S7, 2009.

[13] S. R. Lockhart, M. A. Abramson, S. E. Beekmann et al., "Antimicrobial resistance among Gram-negative bacilli causing infections in intensive care unit patients in the United States between 1993 and 2004," Journal of Clinical Microbiology, vol. 45, no. 10, pp. 3352-3359, 2007.

[14] M. Bubonja-Sonje, M. Matovina, I. Skrobonja, B. Bedenic, and M. Abram, "Mechanisms of carbapenem resistance in multidrug-resistant clinical isolates of Pseudomonas aeruginosa from a Croatian hospital," Microbial Drug Resistance, vol. 21, no. 3, pp. 261-269, 2015.

[15] J. A. Labarca, M. J. Salles, C. Seas, and M. Guzmán-Blanco, "Carbapenem resistance in Pseudomonas aeruginosa and Acinetobacter baumannii in the nosocomial setting in Latin America," Critical Review of Microbiology, vol. 42, no. 2, pp. 276-292, 2016.

[16] D. Muluye, Y. Wondimeneh, G. Ferede et al., "Bacterial isolates and their antibiotic susceptibility patterns among patients with pus and/or wound discharge at Gondar university hospital," BMC Research Notes, vol. 7, no. 1, article 619, 2014.

[17] J. Ruiz, E. Villarreal, M. Gordon, J. Frasquet, A. Castellanos, P. Ramirez et al., "From MIC creep to MIC decline: Staphylococcus aureus antibiotic susceptibility evolution over the last 4 years," Clinical Microbiology and Infection, vol. 22, no. 8, pp. 741-742, 2016. 

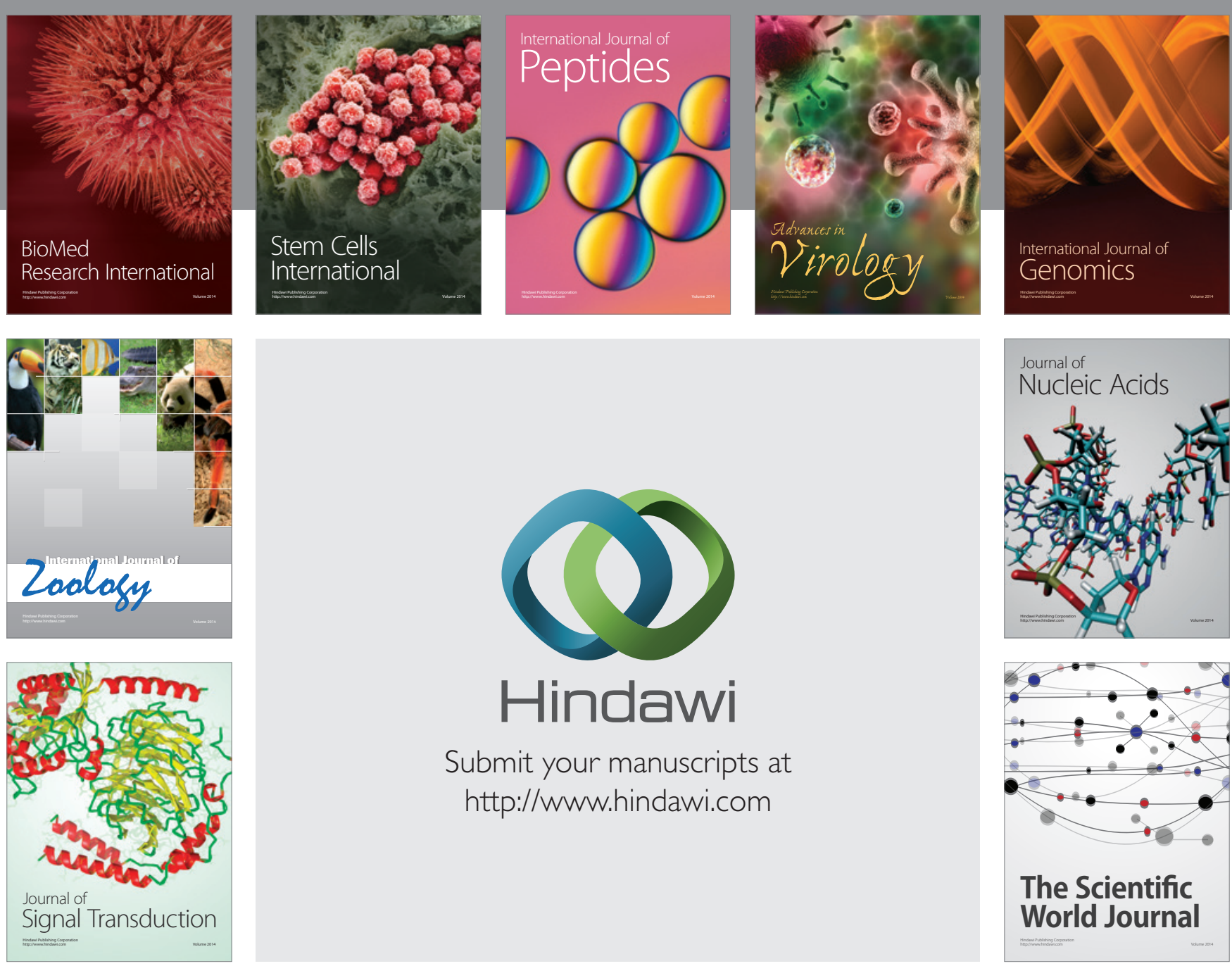

Submit your manuscripts at

http://www.hindawi.com
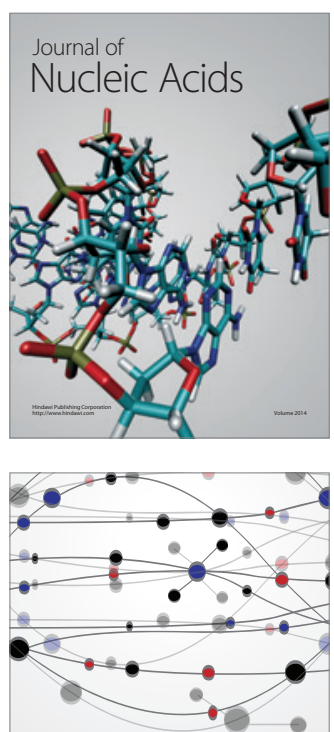

The Scientific World Journal
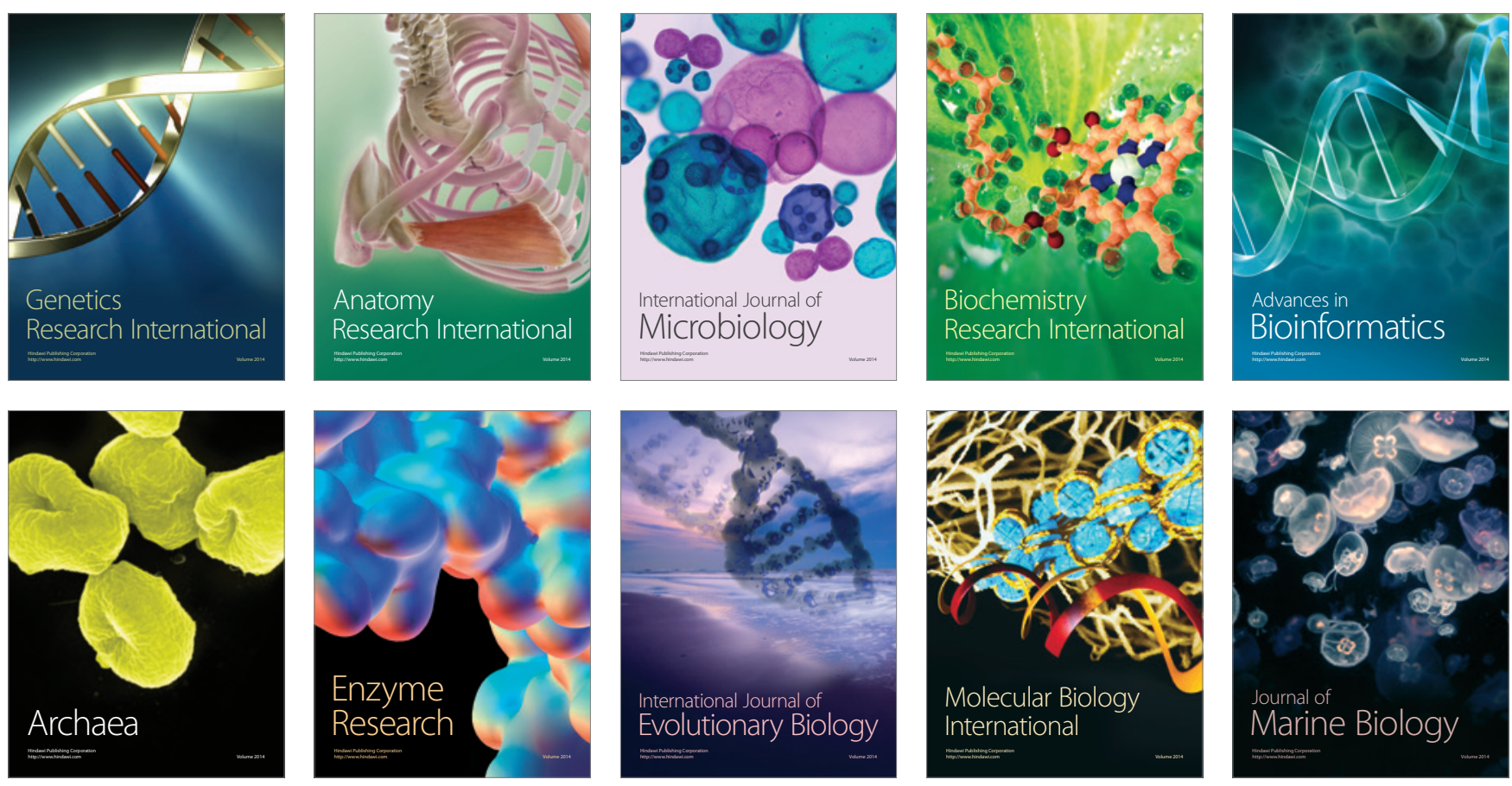